\title{
Inoculation of seven pine species or hybrid seedlings with Korean isolates of pinewood nematode under greenhouse conditions
}

\author{
Kwan-Soo Woo ${ }^{1}$, Do-Hyung LEE $^{2 *}$, Yeong-Bon Koo ${ }^{1}$, Jin-Kie YEO ${ }^{1}$ \\ ${ }^{1}$ Department of Forest Genetic Resources, Korea Forest Research Institute, Suwon 441-847, Korea \\ ${ }^{2}$ Department of Forest Resources, Yeungnam University, Gyeongsan 712-740, Korea
}

Keywords:

pinewood nematode /

susceptibility /

inoculation /

Bursaphelenchus xylophilus /

mortality

(Received 16 May 2008; accepted 27 August 2008)

\author{
Mots-clés : \\ nématode du pin / \\ sensibilité / \\ inoculation / \\ Bursaphelenchus xylophilus / \\ mortalité
}

\begin{abstract}
- Seedlings of seven pine species or hybrids, Pinus densiflora, Pinus thunbergii, Pinus virginiana, Pinus echinata, Pinus koraiensis, Pinus thunbergii $\times$ Pinus massoniana and Pinus $\times$ rigitaeda, were inoculated in a greenhouse with 100, 1000 and 10000 pathogenic nematodes, Bursaphelenchus xylophilus, to compare initial symptom development and to evaluate susceptibility to pinewood nematodes.

- Genetic types were significantly different in the starting day of needle discoloration $\left(\chi^{2}=43.48\right.$; $P<0.001)$ and the period from nematode inoculation to seedling death $\left(\chi^{2}=32.85 ; P<0.001\right)$, but treatment groups were not statistically different in the days from inoculation to seedling death in any of the pine species.

- There was no relationship between seedling mortality and the number of nematodes recovered from infected seedlings. Only eight of the nematode-inoculated seedlings remained alive by day 83 after inoculation, including four seedlings each of $P$. echinata and $P . \times$ rigitaeda grown from bulked seed collections.

- Seedlings from the bulk lots were likely more genetically diverse than those from the single-source lots. A broader genetic representation of pine species or hybrids is suggested for screening for planting stocks resistant to B. xylophilus.
\end{abstract}

Résumé - Inoculation sous serre de semis de sept espèces ou hybrides de pin par des isolats coréens du nématode du pin.

- Des semis de sept espèces ou hybrides de pin, Pinus densiflora, Pinus thunbergii, Pinus virginiana, Pinus echinata, Pinus koraiensis, Pinus thunbergii $\times$ massoniana, et Pinus $\times$ rigitaeda ont été inoculés sous serre par 100, 1000 ou 10000 nématodes pathogènes Bursaphelenchus xylophilus, pour comparer le développement des symptômes à leur début et évaluer la sensibilité de ces essences.

- Des différences significatives ont été trouvées entre types génétiques pour la date de début de décoloration des aiguilles $\left(\chi^{2}=43.48 ; P<0.0001\right)$, ainsi que pour le délai entre l'inoculation et la mort des plants $\left(\chi^{2}=32.85 ; P<0.0001\right)$, mais pas entre traitements, quelle que soit l'espèce.

- Aucune relation n'a été observée entre la mortalité des semis et le nombre de nématodes récupérés des semis infestés. Seulement huit plants inoculés étaient encore vivants après 83 jours, dont quatre de $P$. echinata et de $P . \times$ rigitaeda issus des collections de graines en vrac.

- Les semis des lots de vrac étaient probablement génétiquement plus variés que ceux des lots de source unique. Une plus large représentation des espèces et des hybrides serait nécessaire pour un screening des souches de plantations résistantes à B. xylophilus.

\section{INTRODUCTION}

Pine wilt disease, caused by Bursaphelenchus xylophilus (Steiner \& Buhrer) Nickle, the pinewood nematode (PWN), was first noticed in Korea in 1988 (Choi and Moon, 1989;

*Corresponding author: dhlee@yu.ac.kr
Enda, 1989; Yi et al., 1989). Since then the devastating disease has spread in a northward direction from the southern part of the Korean Peninsula. Pines occupy $23.5 \%$ of the total forested land in Korea and by 2006 pine wilt disease had damaged more than 7800 ha of Pinus thunbergii Parl. and Pinus densiflora Sieb. et Zucc. (Shin and Han, 2006). 
The disease was also found in December 2006 in planted forests of a five-needle pine, Pinus koraiensis Sieb. et Zucc., in the middle of the Peninsula. The $B$. xylophilus recovered from $P$. koraiensis was alleged to have been transmitted by an insect vector, Monochamus saltuarius Gebler, a long-horned beetle (Cerambycidae), which infects healthy trees during maturation feeding on young twigs and shoots. A different species, Monochamus alternatus Hope, is the insect vector for $\mathrm{Pi}$ nus densiflora and Pinus thunbergii (Kwon et al., 2006). In Japan, the PWN is also transmitted by two beetles, $M$. alternatus (in most areas) (Mamiya and Enda, 1972; Morimoto and Iwasaki, 1972) and M. saltuarius in the cooler regions (Sato et al., 1987).

Between 1988 and 2003, several studies were conducted in Korea on a limited number of test seedlings to examine the susceptibility of pine trees to the PWN (KFRI, 2002; Woo et al., 2007), but none were designed to screen for genetic resistance to the nematode using artificial inoculation. For example, seedlings of $P$. densiflora and $P$. thunbergii grown from seeds of natural forests were highly susceptible to nematodes isolated from an infected tree. However, Abies holophylla Maxim. and Picea abies (L.) Karst. were found to be resistant to the disease (KFRI, 2002).

The PWN is considered epidemic in Japan where native forests of $P$. densiflora, $P$. thunbergii and $P$. luchuensis have been heavily damaged (Mamiya, 1983). However, the pathogen is generally endemic in North America, and most North American pine species appear to be resistant to the disease (Dropkin, 1985). Developing hybrid species resistant to PWN is one strategy to prevent damage from the disease, but the resistance may not persist over time or across a variety of environmental conditions. The interspecific hybrid of $P$. thunbergii $\times$ P. massoniana was resistant to the PWN in Japan $(\mathrm{Fu}-$ tai and Furuno, 1979; Mamiya, 1983). However, we confirmed that three-year-old open-pollinated families of $P$. thunbergii, $P$. thunbergii $\times P$. taiwanensis, $P$. thunbergii $\times P$. massoniana and $P$. densiflora were all susceptible to an isolate from $P$. thunbergii (Woo et al., 2007).

The degree of susceptibility of mature pine stands to PWN may vary even when stands are located near each other (Togashi et al., 1992). The density of the inoculum and the age of hosts also appear to influence susceptibility (Kishi, 1999). The objectives of this research were to: (1) determine variation in susceptibility of pine seedlings to pine wilt disease and (2) determine how densities of the nematode are related to the susceptibility of the pines to B. xylophilus.

\section{MATERIALS AND METHODS}

\subsection{Plant materials}

Three- to six-year-old seedlings of seven pine species or hybrids (Tab. I) were grown in nursery beds of the Department of Forest Genetic Resources, Korea Forest Research Institute (KFRI), Kyeonggi Province. The seedlings were transplanted into plastic pots and moved into a greenhouse in spring 2006. The soil used was a mixture of clay, sand, TKS2 Instant (Floragard, Oldenburg, Germany), perlite and vermiculite $(1: 1: 2.5: 0.5: 1[\mathrm{v} / \mathrm{v}])$. TKS2 Instant contains 100 to $400 \mathrm{mg}$ of $\mathrm{N}$ per liter, 150 to $550 \mathrm{mg}$ of potassium oxide per liter, and 100 to $400 \mathrm{mg}$ of phosphorpentoxide per liter.

\subsection{Culture of pinewood nematode}

Bursaphelenchus xylophilus was isolated from naturally diseased $P$. densiflora in Jinju city. The diseased wood was cut into chips of about $1 \mathrm{~cm}$ in length and nematodes were isolated using the Baermann funnel technique for $24 \sim 48 \mathrm{~h}$ at room temperature (ca. 23-26 ${ }^{\circ} \mathrm{C}$ ) (Southey, 1986). The nematodes were multiplied on a fungal mat of Botrytis cinerea Pers. growing on potato dextrose agar and incubated at $25{ }^{\circ} \mathrm{C}$ for about 10 days. They were stored at $4{ }^{\circ} \mathrm{C}$ until used.

\subsection{Artificial inoculations}

Twenty seedlings per seed source (14 seedlings for $P$. thunbergii $\times P$. massoniana) were used in this study. On June 1, 2006, five seedlings of each source were assigned to each of three treatments and one control group. Seedlings in the treatment groups were inoculated with one of three densities of nematodes adjusted to 100, 1000 or $10000 / 100 \mu \mathrm{L}$ sterilized distilled water. Sterilized water was applied to the control seedlings. A wound was made on the main stem of each seedling by removing an area of bark $2 \mathrm{~cm}$ long and $1 \mathrm{~cm}$ wide, and a piece of cotton was placed in the wound. The nematode suspension or sterilized water was pipetted onto the cotton, and covered with parafilm to prevent contamination and water loss. Minimum and maximum temperatures within the greenhouse ranged from $15^{\circ} \mathrm{C}$ to $27{ }^{\circ} \mathrm{C}$ and from $23{ }^{\circ} \mathrm{C}$ to $42{ }^{\circ} \mathrm{C}$ for 83 days, respectively. Subsequent to the inoculation, the seedlings were watered, but no nutrients were supplied. Individual seedlings were examined for needle discoloration daily for the first three weeks after inoculation and then at weekly intervals until the end of the experiment. Pine seedlings were judged to be dead when all of the needles turned brown. The stems and branches of dead seedlings were cut into chips $5 \mathrm{~mm}$ thick and immersed in Baermann funnels to confirm the presence of $B . x y$ lophilus. The total number of extracted nematodes was counted for each seedling. The experiment was terminated when seedlings did not show any further disease development.

\subsection{Data analysis}

The starting day of needle discoloration and the period from nematode inoculation to seedling death were analyzed by seed source with the Kruskal-Wallis One-Way ANOVA (Chi-Square approximation) using SYSTAT 9 statistical software (SYSTAT Software Inc. 2004). The Mann-Whitney U-test was performed to determine whether nematode densities were related to these variables. Seedlings that survived beyond the experimental period were excluded from the analysis of the period between inoculation and seedling death. Species differences were analyzed by analysis of variance (ANOVA) using the SAS-PROC GLM statistical package and type III sums of squares (SAS Institute Inc. 1989). When differences among species were significant at $P<0.05$, least squares means procedures were applied. 
Table I. Age, number of seedlings and seed sources of seven pine species or hybrids inoculated with three densities of Bursaphelenchus xylophilus.

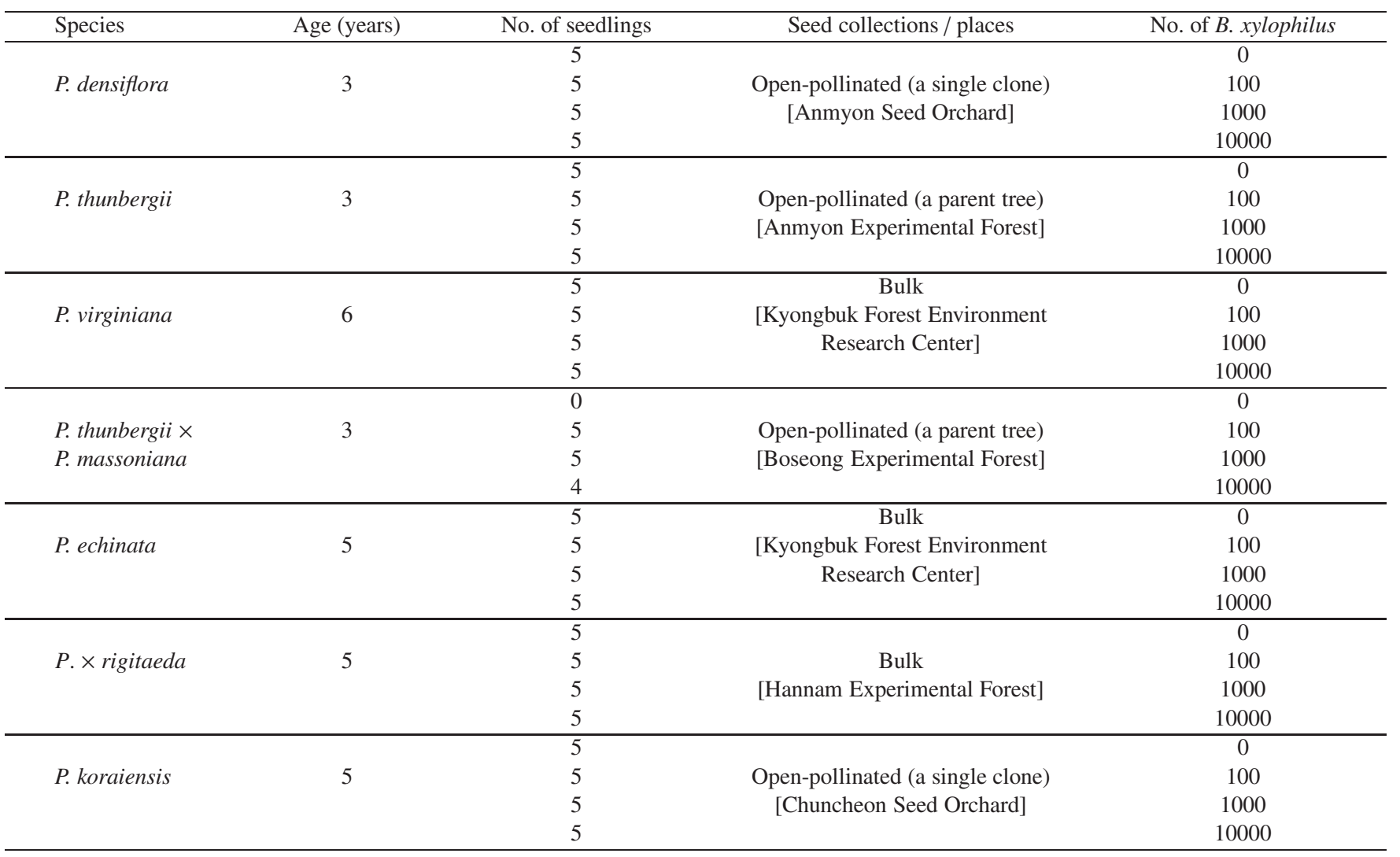

\section{RESULTS}

There was a statistically significant difference $\left(\chi^{2}=43.48\right.$; $P<0.001)$ in the average starting day of needle discoloration among genetic sources and inoculation densities. We found statistical differences in the average starting day of needle discoloration between seedlings inoculated with 100 compared with 10000 nematodes in four of the seven pine species or hybrids (Tab. II). Needles of $P$. thunbergii seedlings inoculated with 10000 nematodes were the earliest to discolor $(\bar{X}=$ 19 days; Fig. 1); those of $P$. echinata inoculated with 100 nematodes were one of the most delayed $(\bar{X}=68$ days $)$. None of the comparisons between inoculations of 1000 compared with 10000 nematodes was statistically significant. The period from inoculation to seedling death was significantly different $\left(\chi^{2}=32.85 ; P<0.001\right)$ among the seven pine species or hybrids, but individual comparisons using the Mann-Whitney U-test showed no statistically significant differences (Fig. 2).

All but four seedlings each of $P$. echinata and $P . \times$ rigitaeda of the nematode-inoculated seedlings were dead by 83 days after inoculation (Fig. 3). There was no relationship between age of seedlings and mortality. No water-inoculated control group seedlings had died by the end of the experiment ( 83 days).

The average number of nematodes recovered from the three nematode treatments varied among the seven pine species or hybrids but not among treatments $(P<0.001$ and $P=0.45$,
Table II. The Mann-Whitney U-test for average starting day of needle discoloration between three densities of nematode in each of seven pine species or hybrids.

\begin{tabular}{lccc}
\hline Species & Densities of & $\mathrm{U}$ & $P$-value \\
& B. xylophilus & & \\
\hline \multirow{3}{*}{ P. densiflora } & 100 vs. 1000 & 6.0 & 0.111 \\
& 100 vs. 10000 & 2.0 & 0.016 \\
& 1000 vs. 10000 & 8.0 & 0.111 \\
\hline P. thunbergii & 100 vs. 1000 & 0.5 & 0.01 \\
& 100 vs. 10000 & 0.0 & 0.004 \\
& 1000 vs. 10000 & 5.0 & 0.075 \\
\hline P. virginiana & 100 vs. 1000 & 8.0 & 0.210 \\
& 100 vs. 10000 & 4.5 & 0.241 \\
$P$. thunbergii $\times$ P. massoniana & 1000 vs. 10000 & 9.0 & $>0.50$ \\
\hline P. echinata & 100 vs. 1000 & 1.0 & 0.008 \\
& 1000 vs. 10000 & 0.0 & 0.018 \\
& 100 vs. 1000 & 4.5 & 0.062 \\
& 100 vs. 10000 & 0.0 & 0.004 \\
& 1000 vs. 10000 & 7.5 & 0.183 \\
\hline & 100 vs. 1000 & 9.5 & $>0.50$ \\
& 100 vs. 10000 & 6.5 & 0.133 \\
& 1000 vs. 10000 & 14 & $>0.50$ \\
\hline
\end{tabular}




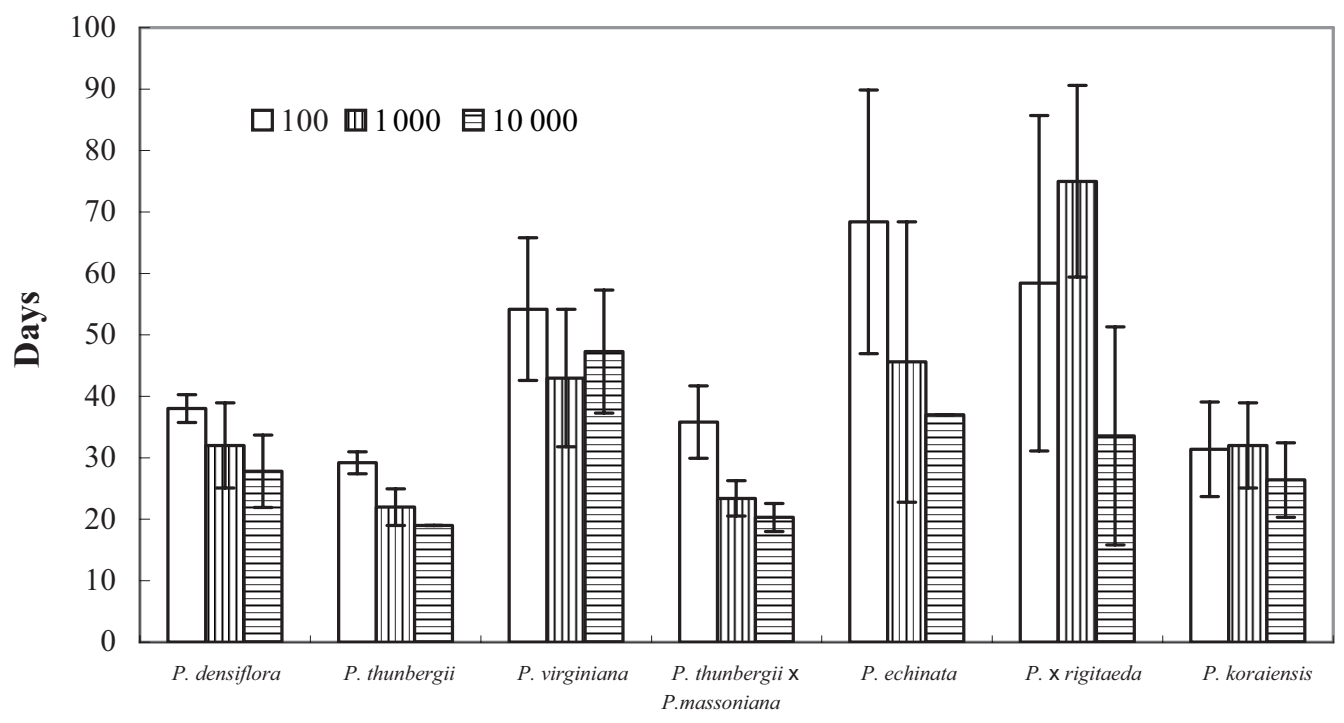

Species

Figure 1. Average number of days from inoculation to beginning of needle discoloration of seven pine species or hybrids inoculated with three densities of B. xylophilus. Error bars are the mean $\pm \mathrm{SD}$ of five replicates.

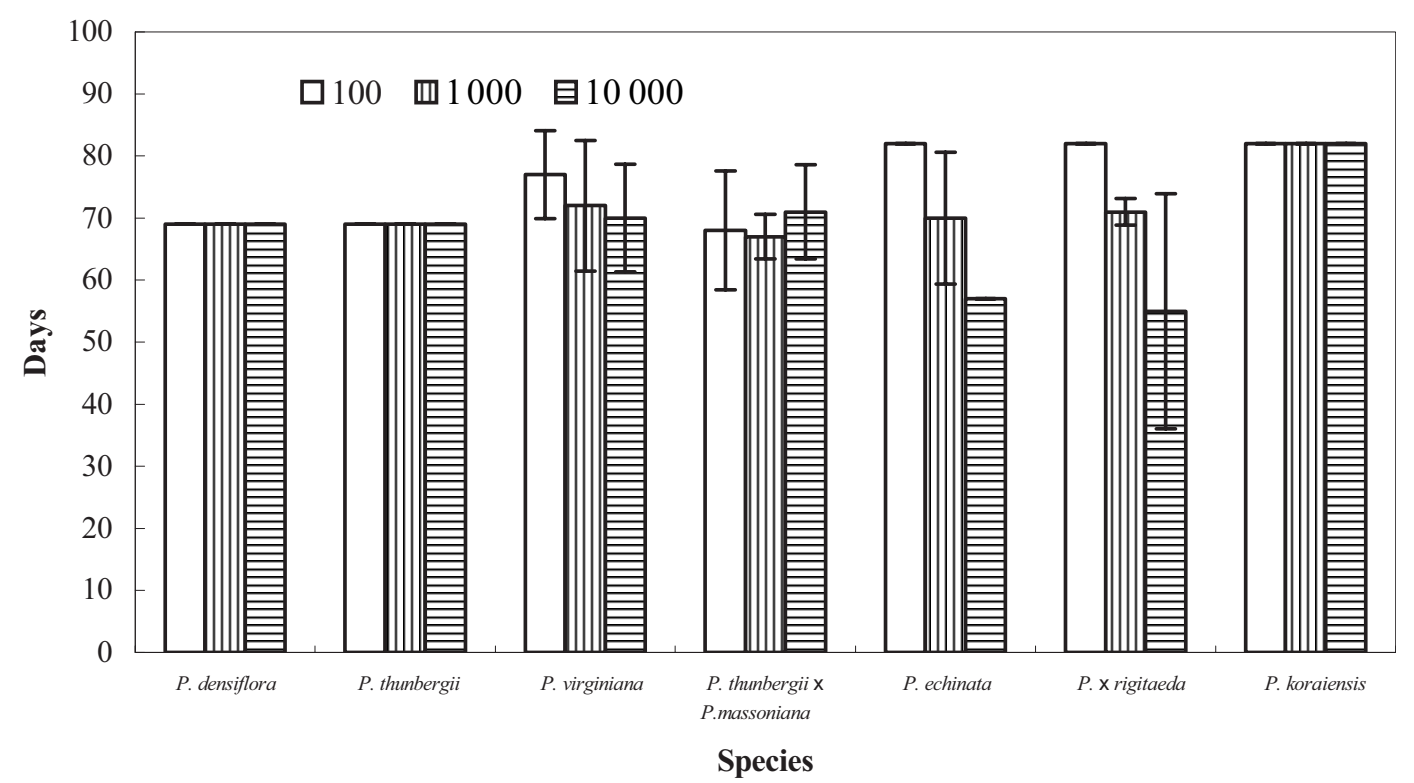

Figure 2. Average days from nematode inoculation to death of seven pine species or hybrid seedlings inoculated with three densities of $B$. xylophilus. The Mann-Whitney U-test showed that there were no significant differences for average days from nematode inoculation to seedling death between three densities of nematodes in each of seven pine species or hybrids. Error bars are the mean \pm SD of five replicates.

respectively, and Fig. 4). The least squares means test showed that differences were significant only between seedlings of P. koraiensis and those of other pines (data not shown). The greatest number of nematodes was isolated from the seedlings of $P$. koraiensis $(\bar{X}=7219$; range: $280-16100)$; the lowest was from the seedlings of $P$. thunbergii $\times P$. massoniana $(\bar{X}=1043$; range: $80-3450)$ (Fig. 4). No nematodes were recovered from the control seedlings at the end of the experiment.

\section{DISCUSSION}

The mechanism by which pine wood nematodes kill trees is unknown. Hypotheses include cell death, cavitation and embolism caused as a result of increased production of volatile terpenes (Kuroda, 1991; Ikeda and Kiyohara, 1995; Ichihara et al., 2000). Regardless of the mechanism, the results of the current study showed all seven pine species and hybrids to be susceptible to PWN. Although previous studies have reported 


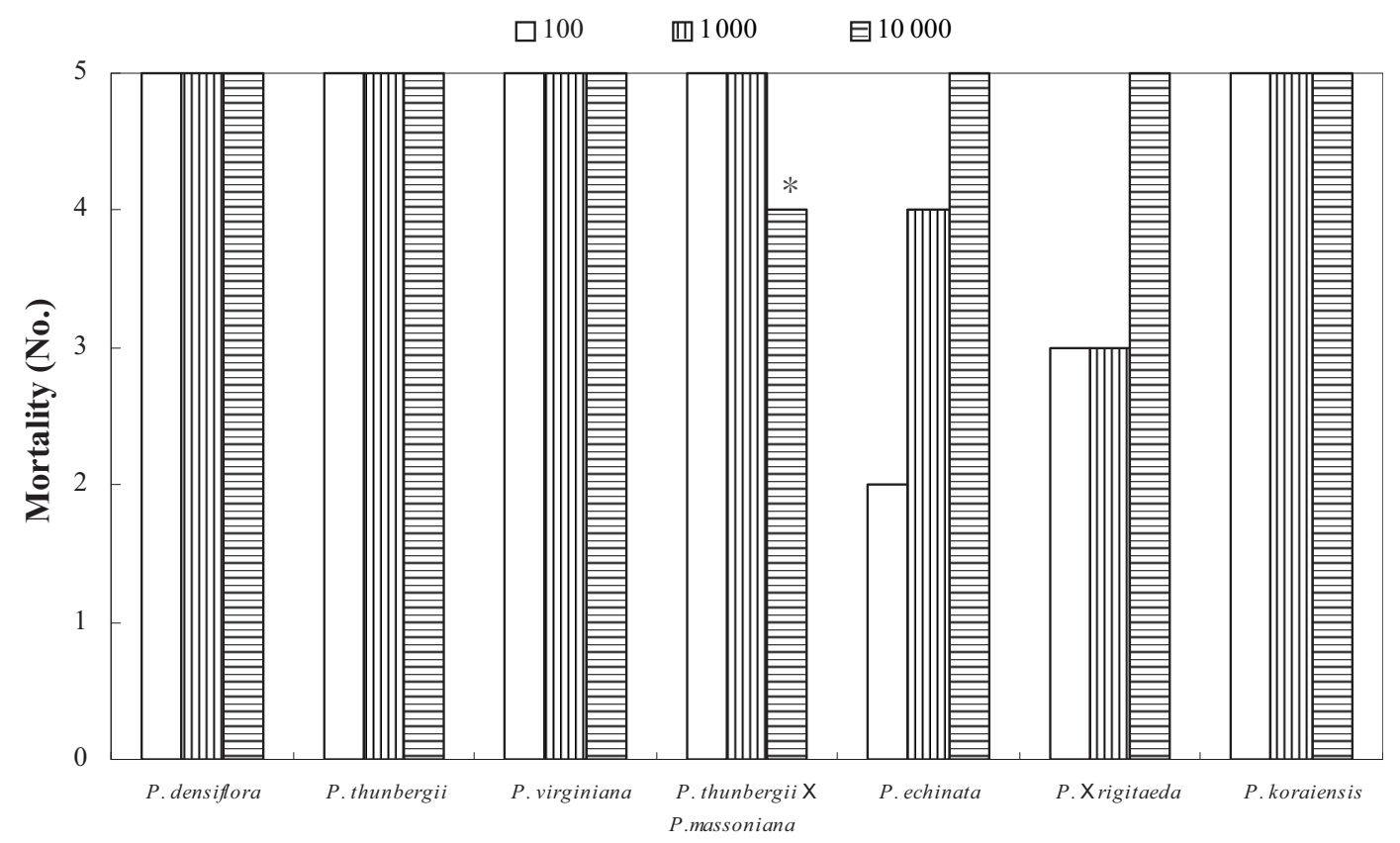

Species

Figure 3. Mortality of seven pine species or hybrid seedlings 83 days after inoculation with three densities of B. xylophilus. Fifteen seedlings from each of the pine species were inoculated with $B$. xylophilus, except $P$. thunbergii $\times P$. massoniana, in which fourteen seedlings were used for the nematode inoculation. None of the control seedlings died during the experiment. *Only 4 seedlings inoculated.

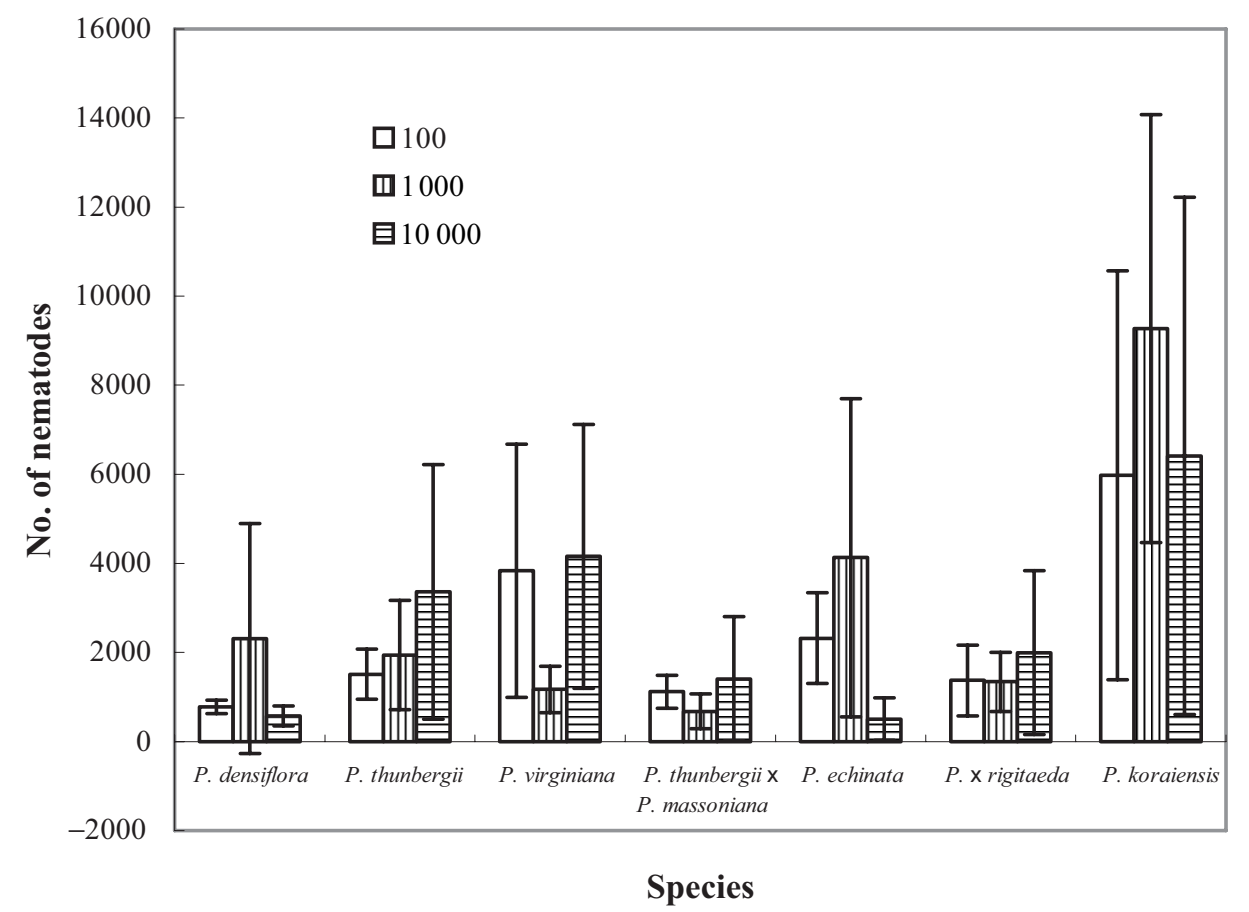

Figure 4. Average number of Bursaphelenchus xylophilus recovered from dead seedlings of seven pine species or hybrids inoculated with three densities of nematodes. Error bars are the mean \pm SD of five replicates. 
pine species to vary in their susceptibility to PWN (Dropkin et al., 1981; Dwinell, 1985; Futai and Furuno, 1979; Yang and Wang, 1989), such discrepancies may be caused by variation in virulence among isolates of $B$. xylophilus, genetic variation in resistance among tested individuals, physiological differences resulting from variation in growth regimes or other environmental factors. For example, all of the six-year-old seedlings of Pinus virginiana in this study died from PWN, but the species was found to be resistant in a study of three-yearold seedlings inoculated in a greenhouse with three isolates of B. xylophilus from the United States (Dwinell, 1985), and Dropkin et al. (1981) reported that $P$. virginiana is moderately susceptible.

Previous studies have shown differences in susceptibility of mature pine species to infection by PWN related to inoculum densities (Akiba and Nakamura, 2005; Kishi, 1999). Mamiya (1983) reported that 30 nematodes per susceptible mature tree of $P$. densiflora and $P$. thunbergii could produce infection, but the level of disease development was slower than with 3000 or 30000 nematodes. In the present study, disease symptoms also appeared later in seedlings inoculated with a lower density of nematodes compared with those inoculated with large numbers (Fig. 1). The starting day of needle discoloration also varied with the combination of densities of nematodes and species (Fig. 1). In a previous test, we found no correlation between mortality of four pine species or hybrids and the densities of B. xylophilus at 3000,5000 and 7000 nematodes (Woo et al., 2007), suggesting even 3000 nematodes per $\mathrm{ml}$ was beyond a critical threshold level of inoculum.

The dispersal fourth stage juveniles ( $\mathrm{J}_{\mathrm{iv}}$ ) of B. xylophilus are transmitted to host trees during maturation feeding of the Monochamus insect vector on young twigs and shoots (Linit, 1990; Mamiya, 1975; Wingfield and Blanchette, 1983), with the transmission rate depending on the age of insect vectors after emergence and number of nematodes they carry (Togashi, 1985). An insect vector carrying more than 10000 nematodes transmitted a maximum of 750 nematodes per adult tree (Togashi, 1985). Thus, the inoculum densities of 1000 and 10000 nematodes per tree in the current study are within the natural range of densities occurring under field conditions. The lowest treatment level in the current study (100 nematodes/tree) may be low compared with field conditions, but inoculation with even this density of inoculum was sufficient to kill 30 of 35 treated seedlings.

Dwinell (1985), and Akiba and Nakamura (2005) found that there was a highly significant correlation between the percent dead and the number of nematodes recovered. In the current study, the number of nematodes extracted from dead seedlings was significantly different among the seven pine species or hybrids, with the fewest recovered from $P$. thunbergii $\times$ P. massoniana (Fig. 4). The relatively small number of nematodes recovered from the dead hybrids may suggest high susceptibility, a relatively unfavorable growth environment for the nematodes or both, but the number of nematodes or their effect was sufficient to kill the seedlings. However, since the 97 of 105 inoculated seedlings had died, there was no direct relationship between seedling mortality and the number of nematodes recovered.
The period from inoculation to death of 10 -year-old $P$. thunbergii was significantly shorter than that of 20-year-old $P$. armandii var. amamiana inoculated with 1000 nematodes, but the latter group did not differ significantly from seedlings of the same age and species inoculated with 100000 nematodes (Akiba and Nakamura, 2005). In the current study, we found a significant difference in time until death among the seven pine species or hybrids, with Pinus koraiensis living the longest for all densities of nematodes. However, seedling age (which varied by only 2 or 3 years) was not a significant factor. The delayed symptom development in $P$. koraiensis may be associated with its chemical composition, as nematicidal compounds, methyl ferulate and 3-0-methyldihydropinosylvin, have been found, respectively, in heartwood and bark of $P$. strobus, another five-needle pine (Hanawa et al., 2001; Suga et al., 1993;).

Among the seven pine species or hybrids tested, the few seedlings that survived to the end of the trial came from bulk lots of $P$. echinata and $P . \times$ rigitaeda, suggesting the possibility that the bulk lots, with a generally higher level of genetic diversity than the single-source lots, included some useful genetic resistance to PWN. Based on this preliminary trial, we recommend further testing of susceptibility of host pine species to B. xylophilus using a broader genetic representation of the species of interest, different inoculum densities, tree ages, and duration of the experiment. Field tests are also recommended to further describe the relative susceptibilities of pine species to $B$. xylophilus. In Korea, a breeding project for resistance to pine wood nematodes has been initiated. Prior to establishing operational plantings with resistant pines, however, improved lots should be tested routinely by artificial inoculation with pine wood nematodes at the nurseries.

Acknowledgements: We gratefully acknowledge the assistance of Dr. Lauren Fins, professor of forest genetics, University of Idaho, Moscow, USA, in critical reviewing of this manuscript.

\section{REFERENCES}

Akiba M. and Nakamura K., 2005. Susceptibility of adult trees of the endangered species Pinus armandii var. amamiana to pine wilt disease in the field. J. For. Res. 10: 3-7.

Choi Y.E. and Moon Y.S., 1989. Survey on distribution of pinewood nematode (Bursaphelenchus xylophilus) and its pathogenicity to pine trees in Korea. Korean J. Plant Pathol. 5: 277-286.

Dropkin V.H., 1985. Pine wilt in the U.S. In: Dropkin V.H. (Ed.), Proceedings of the United States - Japan Seminar: The resistance mechanisms of pines against pine wilt disease, May 7-11, 1984. University of Missouri - Columbia, Extension Publ. No. 116: 3-5.

Dropkin V.A., Foudin A., Kondo E., Linit M., Smith M. and Robbins K., 1981. Pinewood nematode: A threat to U.S. forests? Plant Dis. 65: 1022-1027.

Dwinell L.D., 1985. Relative susceptibilities of five pine species to three populations of the pinewood nematode. Plant Dis. 69: 440-442.

Enda N., 1989. The status of pine wilting disease caused by Bursaphelenchus xylophilus (Steiner et Buhrer) Nickle and its control in Korea. J. Korean For. Soc. 78: 248-253. 
Futai K. and Furuno T., 1979. The variety of resistances among pinespecies to pinewood nematode, Bursaphelenchus lignicolus. Bull. Kyoto Univ. For. 51: 23-36.

Hanawa F., Yamada T., and Nakashima T., 2001. Phytoalexins from Pinus strobus bark infected with pinewood nematode, Bursaphelenchus $x y$ lophilus. Phytochemistry 57: 223-228.

Ichihara Y., Fukuda K., and Suzuki K., 2000. Early symptom development and histological changes associated with migration of Bursaphelenchus xylophilus in seedling tissues of Pinus thunbergii. Plant Dis. 84: 675-680.

Ikeda T. and Kiyohara T., 1995. Water relations, xylem embolism and histological features of Pinus thunbergii inoculated with virulent or avirulent pine wood nematode, Bursaphelenchus xylophilus. J. Exp. Bot. 46: 441-449.

KFRI (Korea Forest Research Institute), 2002. Annual Report on Forest Disease and Insect Control. Korea Forest Research Institute, Seoul, pp. $518-576$.

Kishi Y., 1999. Influence of tree age on wilt and mortality of pines after inoculation with Bursaphelenchus xylophilus. J. Jpn. For. Soc. 81: 330-333.

Kuroda K., 1991. Mechanism of cavitation development in the pine wilt disease. Eur. J. For. Path. 21: 82-89.

Kwon T.S., Lim J.H., Sim S.J., Kwon Y.D., Son S.K., Lee K.Y., Kim Y.T, Park J.W., Shin C.H., Ryu S.B., Lee C.K., Shin S.C., Chung Y. and Park Y.S., 2006. Distribution patterns of Monochamus alternatus and M. saltuarius (Coleoptera: Cerambycidae) in Korea. J. Korean For. Soc. 95: 543-550.

Linit M.J., 1990. Transmission of pinewood nematode through feeding wounds of Monochamus carolinensis (Coleoptera : Cerambycidae). J. Nematol. 22: 231-236.

Mamiya Y. 1975. The life history of the pinewood nematode, Bursaphelenchus lignicolus. Jap. J. Nematol. 5: 16-25.

Mamiya Y., 1983. Pathology of the pine wilt disease caused by Bursaphelenchus xylophilus. Ann. Rev. Phytopathol. 21: 201-220.

Mamiya Y. and Enda N., 1972. Transmission of Bursaphelenchus lignicolus (Nematoda: Aphelenchoididae) by Monochamus alternatus (Coleoptera: Cerambycidae). Nematologica 18: 159-162.

Morimoto K. and Iwasaki A., 1972. Role of Monochamus alternatus (Coleoptera: Cerambycidae) as a vector of Bursaphelenchus lignicolus (Nematoda: Aphelenchoididae). J. Jpn. For. Soc. 53: 210-218.
SAS Institute Inc., 1989. SAS/STAT User's guide, Version 6, 4th ed., vol.2. SAS Institute Inc. USA.

Sato H., Sakuyama T., and Kobayashi M., 1987. Transmission of Bursaphelenchus xylophilus (Steiner et Buhrer) Nickle (Nematoda: Aphelenchoididae) by Monochamus saltuarius (Gebler) (Coleoptera: Cerambycidae). J. Jpn. For. Soc. 69: 492-496.

Shin S.C. and Han H.R., 2006. Current status on research and management of pine wilt disease in Korea. In: Proceedings of the international symposium on current status on research and management of pine wilt disease, Seoul, Korea, 31-40.

Southey J.F., 1986. Laboratory methods for work with plant and soil nematodes, 6th edn. HMSO, London.

Suga T., Ohta S., Munesada K., Ide N., Kurokawa M., Shimizu M. and Ohta E., 1993. Endogenous pine wood nematicidal substances in pines, Pinus massoniana, $P$. strobus and $P$. palustris. Phytochemistry 33: $1395-1401$

SYSTAT Software Inc., 2004. SYSTAT 11, Statistics II. SYSTAT Software Inc., Richmond, CA.

Togashi K., 1985. Transmission curves of Bursaphelenchus xylophilus (Nematoda: Aphelenchoididae) from its vector, Monochamus alternatus (Coleoptera: Cerambycidae), to pine trees with reference to population performance. Appl. Entomol. Zool. 20: 246-251.

Togashi K., Nakamura K. and Takahashi F., 1992. An index of susceptibility of pine stands to pine wilt disease. Appl. Entomol. Zool. 27: 341-347.

Wingfield M.J. and Blanchette R.A., 1983. The pinewood nematode, Bursaphelenchus xylophilus, in Minnesota and Wisconsin: insect associates and transmission studies. Can. J. For. Res. 13: 1068-1076.

Woo K.S., Kim Y.S., Koo Y.B., Yeo J.K. and Moon, Y.S. 2007. Variation in susceptibility of pine species seedlings with the pinewood nematode, Bursaphelenchus xylophilus, in greenhouse, Plant Pathol. J. 23: $70-75$.

Yang B. and Wang Q., 1989. Distribution of the pinewood nematode in China and susceptibility of some Chinese and exotic pines to the nematode. Can. J. For. Res. 19: 1527-1530.

Yi C.K., Byun B.H., Park J.D., Yang S.I. and Chang K.H., 1989. First finding of the pinewood nematode, Bursaphelenchus xylophilus(Steiner et Buhrer) Nickle and its insect vector in Korea. Res. Rep. For. Res. Inst. 38: 141-149. 